\title{
Influence of Lecturer Immediacy on Students' Learning Outcomes: Evidence from a Distance Education Program at a University in Saudi Arabia
}

\author{
A. Al Ghamdi
}

\begin{abstract}
Research on communication behaviours in fostering effective learning outcomes has become important, particularly in the distance education setting, where there is no face-to-face communication. Given the issue of physical distance between lecturer and students, the concept of behavioural immediacy aims to encompass behavioural styles that simulate a sense of co-presence in mediated communications to compensate for the lack of direct verbal contact and body language cues. Immediacy behaviours practised by the lecturer in virtual classrooms may reduce their psychological distance from students, creating a more social environment and increasing sensory stimulation, to aid the learning process.

This research was undertaken at a university in Saudi Arabia (a premier provider of distance education courses) to investigate the influence of lecturer immediacy (verbal and non-verbal) on the affective and cognitive dimensions of learning in a virtual classroom environment. The results showed a positive significant relationship between affective/cognitive learning and verbal/non-verbal immediacy of lecturers in virtual classrooms. Some gender differences were found showing that male students were more willing than female students to learn when the lecturer practised immediacy behaviours.
\end{abstract}

Index Terms-Distance education, lecturer e-immediacy, verbal and non-verbal immediacy, affective learning, cognitive learning.

\section{INTRODUCTION}

With the rise of digital education in the $21^{\text {st }}$ century, many universities around the world are striving to offer quality online educational courses. In online classrooms, the sense of physical and psychological separation between the lecturer and students has been a focal point of research in distance education [1]. Numerous scholars have argued that lecturer immediacy can reduce the sense of physical and psychological distance between students and lecturers [2]-[4]. Lecturer immediacy encompasses behavioural practices adopted by the lecturer in the virtual classroom that can imbibe a sense of co-presence with students.

This study was conducted to examine the influence of lecturer immediacy on students' learning outcomes at a virtual classroom in a distance education course based in Saudi Arabia. In particular, this research explores immediacy behaviours that can be practised on text-based platforms of communication, such as email, discussion forum, chat portals etc. It assesses the impact of lecturer immediacy on the

Manuscript received May 5, 2015; revised September 22, 2015.

A. Al Ghamdi is with Victoria University, Australia (e-mail abukhalidaus@hotmail.com). affective and cognitive dimensions of learning. The following questions will be examined in the paper:

- Is there any relationship between verbal and non-verbal practices of lecturer immediacy and students' affective and cognitive learning in online classrooms offered by a targeted Saudi university?

- Are there any significant differences between female and male participants' perceptions on this issue in online classroom offered by a targeted Saudi university?

\section{BACKGROUND}

Distance education was first defined by Michael Graham Moore [5] during the 1972 World Conference of the International Council for Correspondence Education as an instructional method where teaching is facilitated through communication by print, electronic, mechanical, and other devices. In Moore's words, distance education is "teaching and planned learning in which teaching normally occurs in a different place and time from learning, requiring communication through technologies as well as special institutional organization".

With the widespread availability of technological innovations such as radio, television, computers, and the internet, the method of delivery used in distance education has expanded over the decades. In the history of distance education, correspondence courses can generally be considered as the first generation of distance education, open universities as second, and digital distance education as the third generation. This third generation of distance education is that of the "tele-learning generation" where interactivity has been made possible through audio-conferencing and video-conferencing. This marked the first step away from totally asynchronous models of distance education towards an instructional model facilitating synchronous communication with the help of computers where participants can communicate in real time. E-learning has been defined as the use of information and computer technologies to facilitate learning [6].

To capitalise on the opportunities afforded by online distance education, the Saudi government has focused on improving this sector in its broader plan of utilising education to provide skills and employment opportunities to its citizens. Distance education has seen high enrolments of Saudi women as they can access education from the security of their home given the cultural restrictions on women's movement in the country Alebaikan and Troudi [7]. Recently, the Ministry of Education established the National Centre for E-Learning and 
Distance Learning to increase their service capacity through e-learning and distance learning programs to make higher education more accessible to a greater number of citizens. Many leading universities in the country have boosted their distance education offerings and focused on ICT development in the distance education system.

The main rationale behind distance education is to enable students to study anytime and anywhere. The distance education classroom is independent of constraints associated with spatial and physical proximity as long as learners accept the course frameworks and tackle their workload independently. This gives students the clear advantage of studying at their own pace, where they can schedule their study load in line with their individual needs. With these features of flexible scheduling and learning at convenience, distance education allows people with other work or life commitments to access higher education.

Achieving interaction success in distance education is important for instructor guidance, student activities, feedback, and other social exchanges or collaborative activities. Interaction in distance education involves feedback loops where lecturer and learners exchange responses in a mutual discourse through teaching technologies afforded by audio/video channels on computer-mediated communication [8], [9]. Computer-mediated communication in different forms, whether video/audio-conferencing, chat forums, emails, enable robust interactions that allow prompt response and synchronous interchange in real time. Video-conferencing may even approximate interactions in traditional classroom situations with visual presence of participants and their body language cues.

This does not necessarily mean that digital communication can completely simulate face-to-face interactions between lecturer and students as it happens in traditional classrooms. Indeed, mediated communication is often assumed to be less effective compared to traditional classrooms because it lacks the sense of understanding that can be imparted in a face-to-face conversation [10]. Since the lecturer's communication is mediated to the student in online-based distance education, this type of virtual classroom lacks the kind of behavioural cues that deepen face to face interaction. It can be difficult for the lecturer and students to participate in the conversation in a seamless manner as in real life interactions. This is because communication in distance education environment lacks the three-dimensionality of physical communication, gestures, local context, and other cues to aid mutual understanding. The lack of proximity may lead open to misinterpretation and misunderstanding. Given the issue of physical and psychological distance in distance education environment, this study focuses on the importance of lecturer immediacy in closing this gap between lecturers and students.

\section{LITERATURE REVIEW}

\section{A. Lecturer Immediacy}

The question of behavioural immediacy has been raised in several studies examining the importance of the sociality of environment in distance education courses. According to
Richmond [11], "Immediacy is a perception of physical or psychological closeness". Immediacy behaviours encompass a range of verbal and non-verbal behaviours that can be used in online media to symbolically communicate non-verbal cues of body language and verbal cues of expressive phrases as they would in a real life conversation [12]. These behaviours are aimed at increasing closeness, encouraging communication, facilitating student input and self-disclosure, creating a sense of belonging, and establishing cognitive presence.

Lecturer immediacy is a relevant concept in online distance education environment as learners' interaction with their lecturer is the most significant contributor and mediator of the whole learning process. Lecturers' act as promoters of collaborative learning, provide expertise, monitor performance, and respond to feedbacks. The relationship between lecturer immediacy and student influences how students feel about their study responsibilities, relationship with peers and lecturer, and overall perception of the course. The lecturer is responsible for structuring the amount of time and energy spent by students in educationally sound activities.

A lecturer immediacy can direct the discussion, communicate lecture content, and mediate interactions properly online-based distance education classrooms when the students have a sense of familiarity and proximity to the lecturer in. The practices to imbibe a sense of immediacy can take verbal and non-verbal forms. According to Velez and Cano [13], non-verbal immediacy is a more implicit style of imparting immediacy as it is "largely a relational language perceived to convey affective feelings of warmth, closeness, and belonging". These can include cues of physical orientation, called 'body language' in the popular vernacular, such as, smiling, engagement in eye contact, using direct body orientation and overall body movement and gestures. In verbal immediacy practices, Velez and Cano [13] count verbally expressive stylisations, such as "syntactic expressions of present or past tense verbs, probability (will vs may), ownership statements (my/our class), and inclusive references (we vs. I) (p.77)".

\section{B. Affective/Cognitive Learning}

Lecturer immediacy behaviours humanises communication and reduces perceived distance between lecturer and students, but the critical issue is to validate that lecturer immediacy has a direct influence on students' learning outcomes. This paper follows previous research that examine two aspects of learning outcomes in terms of its affective and cognitive dimensions Gorham [4], Baker [14].

Affective learning in general takes a humanistic approach to education where the impact of individual thinking, emotions, and feeling on learning are taken into account. The theory of affective learning emphasises the partnership between cognition and emotion and the role of a person's views and values in his or her understanding and effective use of knowledge and skills. Here, students' beliefs, emotions and attitudes not only manifest their experience of the program, but determine their learning outcomes. Affective learning is critical, particularly, for students who are more spontaneous and less linear in their approach to learning. Such students seek emotional experience to truly assimilate 
knowledge. Lecturer immediacy has been proved to be effective in improving affective learning in online learning classes in previous research by [14], [15].

Cognitive learning in general refers to higher mental processes such as attention, remembering, perceiving, and use of memory that enable better understanding of things around us. In one of the earliest studies in this field, distributed mental aptitudes associated with cognitive learning into six classes: information (review of data), perception (comprehends the importance and can give an understanding), application (applies learned ideas in new circumstances), dissection (partitions more intricate ideas into its parts and can give association), composition (can draw from different ideas to make new thought structures and thoughts), and assessment (can make judgments about the quality and estimation of plans and materials). Learning happens when any of these six are achieved, but a full scale of cognitive learning involves moving up this grade of categories signalling progress from less difficult to more complex learning. This approach to learning sees it as an actively constructivist process where students select and organise informational input, evaluate it with previous knowledge, identify the most relevant ideas, apply the information effectively, and reflect on the outcome of the learning process. There are a few studies that have linked lecturer immediacy behaviour with students' cognitive learning [15]. It has also been shown that cognitive learning can be improved by lecturer immediacy when affective learning mediates between them [16].

\section{Methodology}

\section{A. Sampling}

The target population of this study consists of undergraduate male and female students enrolled in online courses of multiple subjects (e.g. Islamic culture, English language, mathematics, sciences, and history) at a university in Saudi Arabia. The participants were invited via email to participate in a study exploring perceptions of their learning outcomes. They were directed to the link for the questionnaire on Survey Monkey Website (SMW) or directly sent the questionnaires by technical support of distance education courses by email. About 612 students were approached, and 413 participants completed and returned the questionnaires. There were 296 female and 117 male respondents in all. The participants completed four questionnaires on the online survey.

\section{B. Measurements}

There are four variables to be measured in the survey. The first and second questions examined the students' perceptions for verbal immediacy behaviour lecturer (VIBL) and non-verbal immediacy behaviour lecturer (NVIBL). In this study, the forms of behavioural practices of immediacy are restricted to text-based behaviour that can replicate a sense of real life interaction. The verbal immediacy behaviours practices used in this study include syntactical expressions, i.e. phrases, statements, pronouns, that induce a sense of directness and familiarity. The non-verbal immediacy behaviours include which approximate the sense of physical interaction of face-to-face conversations. These include any sort of expression communicating the lecturer's gestures, facial expressions, body movement, gaze etc. In this manner, the two measurements of verbal and non-verbal immediacy developed by Farwell [3] were adapted to reflect such text-based practices.

- Verbal immediacy behaviours in text-based environment include practices, such as, exchanging of personal anecdotes or experiences between lecturer and students, using humour, and calling students by his or her first or last name.

- Non-verbal immediacy behaviours in text-based environment include practices, such as, using capital letters to impress the message (GOOD), using emoticons in chat or discussion forums $(;), 0$,$) to convey facial$ expressions or body language gestures.

These measures for students perception of verbal and non-verbal immediacy were evaluated by multiple choice of Likert scale responses degree $(1=$ never, $2=$ rarely, $3=$ occasionally, 4 = often, and 5 = very often).

The affective and cognitive learning measurements were implemented as the dependent variables in the survey. The 16 items of affective learning developed by [2] were used in this survey. The cognitive learning measurement developed by Hiltz [17] was also used. The students rated their perceptions of these variables in five Likert scale degrees of $1=$ strongly disagree, 2 = disagree, $3=$ neutral, $4=$ agree, $5=$ strongly agree.

\section{REsults AND Discussion}

\section{A. Results}

The data of this study were analysed via an independent sample t-test (Table I) to determine if there was significant differences in the results between male and female students. Results found that there were significant differences in gender scores between male and female participants in both verbal and non-verbal immediacy scores. The $t$-test showed a variance of; $t(411)=4.564, p<.001)$ for the first and $t(411)$ $=-12.14, p<.001$ ) for the second. However, for affective learning variable, the result showed that there were no significant differences between male and female participants; $t(411)=.837, p=.403$. Similarly, there were no significant differences in scores for cognitive learning between male and female participants; $t(411)=.079, p .937$.

TABLE I: COMPARISON OF VIBL, NVIBL, AL AND CL MEAN SCORES BETWEEN GENDER (FEMALE OR MALE STUdENTS)

\begin{tabular}{cccccc}
\multicolumn{7}{c}{ BETWEEN GENDER (FEMALE OR MALE STUDENTS) } \\
\hline Female & \multicolumn{3}{c}{ Male } & $t$-test \\
\hline Variables & $M$ & $S D$ & $M$ & $S D$ & $P$-Value \\
\hline VIBL & 2.96 & 0.62 & 2.66 & 0.70 & .001 \\
NVIBL & 2.81 & 0.58 & 3.70 & 0.82 & .001 \\
Al & 3.16 & 1.23 & 3.04 & 1.58 & .452 \\
CL & 3.96 & 0.75 & 3.95 & 0.92 & .943 \\
\hline
\end{tabular}

VIBL: Verbal Immediacy Behaviour Lecturer,

NVIBL; Non-verbal Immediacy Behaviour Lecturer

$\mathrm{AL}$ : Affective Learning;

CL: Cognitive Learning

There was a clear gender difference in the mean scores for VIBL and NVIBL. The mean scores of VIBL were higher in 
the female participants than the male students, while the mean scores of NVIBL were higher for male participants than female students. On the other hand, there was not much variation in mean scores of affective and cognitive learning between female and male participants.

The bivariate correlation test was used to examine the association between verbal and non-verbal immediacy as independent variables. Then, their influence on affective and cognitive learning as dependent variables was also estimated. Table II shows the relationship results for male and female students. The scores for female respondents in the test were in the upper diagonal region, while the responses from the male participants were in the lower diagonal.

TABLE II: RELATIONSHIPS BETWEEN INDEPENDENT AND DEPENDENT VARIABLES FOR BOTH MALES AND FEMALES

\begin{tabular}{lcccc}
\hline Variables & VIBT & NVIBT & AL & CL \\
\hline VIBT & & $.65^{* *}$ & $.33^{* *}$ & $.45^{* *}$ \\
NVIBT & $.44^{* *}$ & & $.34^{* *}$ & $.53^{* *}$ \\
AL & $.20^{* *}$ & $.39^{* *}$ & & $.45^{* *}$ \\
CL & $.19^{*}$ & $.52^{* *}$ & $.50^{* *}$ & \\
*Significant at the .05 level (2-tailed). & &
\end{tabular}

**Significant at the .01 level (2-tailed).

VIBL: Verbal Immediacy Behaviour Lecturer,

NVIBL: Non-verbal Immediacy Behaviour Lecturer

AL: Affective Learning;

CL: Cognitive Learning

For female participants, the results of Pearson correlation showed that there was significant correlation across all variables at the .01 level (2-tailed) and .05 level (2-tailed). The relationship between verbal and non-verbal immediacy with affective learning were found to be positive and moderate. Similarly, the relationship between verbal and non-verbal immediacy with cognitive learning was found to be significant and moderately positive.

For male participants, the relationship between all variables were significant at the .01 level (2-tailed) and .05 level (2-tailed). The correlation between verbal and non-verbal immediacy of lecturer were found to be significantly positive and moderate. The association between affective learning and verbal immediacy was found to be moderately positive, while the relationship of affective learning with non-verbal immediacy was found to be positive but weak. In contrast, the correlation between verbal immediacy and cognitive learning was found to be positive but weak, and the relationship between non-verbal and cognitive learning was found to be moderately positive.

\section{B. Discussion}

With the advancement in technologies allowing instantaneous messaging or live video interactions, it is hoped that distance education can replicate the behavioural immediacy in interaction achieved in traditional classrooms. Consequently, the nature of interaction that is enabled by computer-mediated communication in distance education was analysed, particularly in terms of its capacity to replicate traditional face-to-face interactions within text-based communication behaviour. Immediacy in interpersonal behaviour reduces the psychological distance between lecturer and students, increases sensory stimulation through numerous communication channels, and aids the learning process positively. The report of this study has showed that the correlation between verbal and non-verbal and affective and cognitive learning were moderate to weak positive significant by adopting lecturer practices of e-immediacy behaviour.

The findings observed in this study mirror those of the previous studies that have examined the impacts of lecturer immediacy verbal and non-verbal on student affective learning [3], [18]-[21]. For example, Credence [22] found that there were significant differences in students' affective learning based on the application of lecturer immediacy behaviour in an online course. This result may be explained by the fact that verbal and non-verbal behaviours of lecturer immediacy, such as calling the students with their first name, using the collective noun, were able to instil a sense of familiarity and camaraderie among the students. Affective learning occurs when the students feel genuine concern and interest from the lecturer, and their overall experience of the interaction is warm and personable.

The positive result for cognitive learning result is consistent with [3] which compared the differences in means scores between an online and traditional classroom to assess the importance of lecturer immediacy. There was a significant relationship between verbal and non-verbal immediacy with cognitive learning in the online learning environment as this relationship showed the highest scores. The use of immediacy practices, such as using capital letters to stress a point, prompt response, can impart a clear understanding of the course content as well as the basic learning goals.

The gender differences in the results were quite apparent. According to Burgoon (1995) [23] (as cited in Guerrero, 2013), several studies on gender roles in immediacy behaviour found that there were differences in perceptions of lecturer immediacy between female and male students. Females preferred submissive visual cues of immediacy behaviour, such as head tilt, silence, smiling face, kind words, less talk. In contrast, male lecturers may tend to display these behaviours less than female. Further, given the gender disparity in a conservative country like Saudi Arabia, gender difference in the awareness of use of technology, behavioural norms, and social interaction, may have compounded the difference in the results observed here in this study.

\section{CONCLUSION}

In this study, the importance practices of the lecturer verbal and non-verbal immediacy in teaching and learning content has been examined in terms of students affective and cognitive learning outcomes in distance education environment. This study has revealed that the correlation between a lecturer's verbal and non-verbal practices of e-immediacy behaviour and a student's affective and cognitive learning are moderate to weak positive. The study has found that a lecturer's verbal and non-verbal immediacy can be compatible with transactional distance theory. This is particularly the case when the lecturer uses up-to-date e-learning features. Additionally, integrating the concept of lecturer immediacy and transactional distance theory can reduce the feeling of distance between students and lecturers 
in the distance education environment. Moreover, it can influence the attitudes that students hold regarding their distance education classes. The concepts of transactional distance theory and lecturer immediacy practices can combine to promote effective communication between students and lecturers. This communication can, in turn, improve the learning outcomes of students in the online classroom environment.

The findings of this study are timely, given that there has been an increased focus on distance education courses in Saudi Arabia; and universities worldwide are promoting e-learning and virtual classrooms. Also, the result are very significant to develop the theory of lecturer verbal and non-verbal immediacy in the context of virtual classrooms in Saudi universities. It have a contribution for how behavioural modification can overcome the barrier of psychological distance in online interactions between lecturers and students. These developments suggest that the conventional classroom may eventually be replaced by the virtual classroom.

There are some limitations of this study. First, the impact of immediacy was based unilaterally on perceptions reported in one survey; the design of this study did not involve control and experiment groups to substantiate change in perceptions that would have more firmly proved the impact of lecturer e-immediacy. Secondly, the study was conducted on text-based practices of immediacy behaviour. Ideally these limitations could be addressed with a future study examining immediacy practices afforded by video camera or digital photos.

Note: this study is part of a $\mathrm{PhD}$ research project that is sponsored by the Saudi Ministry of Higher Education.

\section{REFERENCES}

[1] K. D. Bohnstedt et al., "Instructor interaction and immediacy behaviors in a multipoint distance educational environment: Using technology to improve low-incidence teacher preparation," Journal of Special Education Technology, vol. 28, no. 4, 2013.

[2] K. I. Khoo, "Impact of immediate faculty behaviors on the learning of Japanese undergraduates in a US distance education program: Immediacy in cross-cultural instructional communication," THE Claremont Graduate University, 2010,

[3] C. L. Farwell, "Measurements of effective teaching in the traditional and online contexts: Teacher immediacy, student motivation, \& student learning," Western Illinois University, 2011.

[4] J. Gorham, "The relationship between verbal teacher immediacy behaviors and student learnin," Communication Education, vol. 37, no. 1, pp. 40-53, 1988

[5] M. G. Moore, "Toward a theory of independent learning and teaching," The Journal of Higher Education, pp. 661-679, 1973.

[6] J. Dron, "Control and constraint in e-Learning: choosing when to choose," Idea Group Pub, 2007.
[7] R. Alebaikan, and S. Troudi, "Blended learning in Saudi universities: Challenges and perspective," Research in Learning Technology, vol. 18, no. 1,2010 .

[8] F. Belanger, and D. Jordan, "Evaluation and implementation of distance learning: Technologies, tools and techniques." Idea Group Publishing, 1999.

[9] Information Research Association, "Web-based education: Concepts, methodologies, tools and applications," Information Science Reference, USA, 2010.

[10] F. Dabaj, Analysis of Communication Barriers to Distance Education: A Review Study, 2011.

[11] V. Richmond, "Teacher nonverbal immediacy," Communication for Teachers, vol. 65, p. 82, 2002.

[12] A. Al Ghamdi, A. Samarji, and A. Watt, Essential Considerations in Distance Education in KSA: Teacher Immediacy in a Virtual Teaching and Learning Environment, 2016.

[13] [13]. J. J. Velez, and J. Cano, "The relationship between Teacher immediacy and student motivation," Journal of Agricultural Education, vol. 49, no. 3, pp. 76-86, 2008.

[14] C. Baker, "The impact of instructor immediacy and presence for online student affective learning, cognition, and motivation," Journal of Educators Online, vol. 7, no. 1, 2010.

[15] J. D. Baker, "An investigation of relationships among instructor immediacy and affective and cognitive learning in the online classroom," The Internet and Higher Education, vol. 7, no. 1, pp. 1-13, 2004.

[16] J. I. Rodríguez, T. G. Plax, and P. Kearney, "Clarifying the relationship between teacher nonverbal immediacy and student cognitive learning: Affective learning as the central causal mediator," Communication Education, vol. 45, no. 4, pp. 293-305, 1996.

[17] S. R. Hiltz, "A virtual classroom on EIES: Final evaluation report," New Jersey Institute of Technology, 1988.

[18] A. A. Asiri, The Impact of Instructor Immediacy on College Student Communication and Learning Outcomes in Saudi Arabia, Victoria University Melbourne, Australia, 2013.

[19] C. Baker, "The impact of instructor immediacy and presence for online student affective learning, cognition, and motivation," Journal of Educators Online, vol. 7, no. 1, pp. 1, 2010.

[20] L. J. Christensen, and K. E. Menzel, "The linear relationship between student reports of teacher immediacy behaviors and perceptions of state motivation, and of cognitive, affective, and behavioral learning," 1998.

[21] M. Allen, P. L. Witt, and L. R. Wheeless, "The role of teacher immediacy as a motivational factor in student learning: Using meta-analysis to test a causal model," Communication Education, vol. 55 , no. 1, pp. 21-31, 2006.

[22] B. Credence, "The Impact of instructor immediacy and presence for online student affective learning, cognition, and motivation," Journal of Educators Online, vol. 7, 2010.

[23] J. K. Burgoon, "Cross-cultural and intercultural applications of expectancy violations theory," Intercultural Communication Theory, vol. 19, pp. 194-214, 1995.

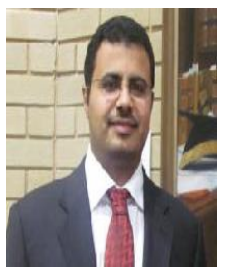

Abdullah Al Ghamdi is a $\mathrm{PhD}$ candidate at the College of Education, Victoria University, Melbourne. His $\mathrm{PhD}$ research focuses on the topic of technology in education. He received his master of education in e-learning from La Trobe University. Additionally, he is a high school teacher in Arabic language in the capital city of Saudi Arabia. His future research interest is in distance education, blended learning and ICT in education. 